\title{
Technological catch-up and the role of universities: South Korea's innovation-based growth explained through the Corporate Helix model
}

Myung-Hwan Cho

Correspondence:

mcho@konkuk.ac.kr

Department of Biological Sciences, College of Bioscience and

Biotechnology, Konkuk University, Seoul 143-701, Republic of Korea

\begin{abstract}
Linkages between industry and university have become crucial for knowledge discovery and driving industrialization within fast-paced global competition and technological evolution. This study offers a pair-wise cross-case analysis of the transitioning of Pohang University of Science and Technology (POSTECH) and Sungkyunkwan University (SKKU) to become entrepreneurial universities through the Corporate Helix model. POSTECH and SKKU demonstrated divergent routes but convergent outcomes in technological catch-up during the double helix formation stage. Through the relationship triad POSTECH shares with the Industry and Government after being established by Pohang Steel Company, it has been committed to launching Korea into the forefront of innovative science and technology in the twenty-first century. As a result of its acquisition and intensive investment from Samsung for almost over two decades, SKKU has become one of the top schools in South Korea while interacting closely with the industry and government to cultivate the efficacy of South Korea's national innovation system. The Corporate Helix model takes into account the university which lacks the resources and capability to become entrepreneurial and to participate in a nation's technological catch-up to innovation-based growth. The cases of POSTECH and SKKU offer key propositions that a university can be established or acquired by the industry and through this partnership undergo transformation to become entrepreneurial.
\end{abstract}

JEL: 125, O31, O38

Keywords: Triple helix; Corporate helix; University; Industry; Government; Technological catch-up; Innovation; South Korea

\section{Multilingual abstracts}

Please see Additional file 1 for translations of the abstract into the five official working languages of the United Nations and Portuguese.

\section{Background}

The function of the university as a source of new knowledge has grown in significance over the years given the emergence of the knowledge-based economy (Etzkowitz et al. 2000; Eom and Lee 2010). The linkages of industry to university become necessary not

(c) 2014 Cho; licensee Springer. This is an Open Access article distributed under the terms of the Creative Commons Attribution License (http://creativecommons.org/licenses/by/2.0), which permits unrestricted use, distribution, and reproduction in any medium, provided the original work is properly cited. 
only for knowledge discovery but also for driving industrialization within fast-paced global competition and technological evolution (Bettis and Hitt 1995; Etzkowitz and Leydesdorff 1997; Hwang et al. 2003). Universities have therefore proven to become an integral part of a majority of national innovation systems (NIS).

Two contrasting views exist with regards to the role of a university, i.e., the Triple Helix thesis and the New Economics of Science (Eom and Lee 2010). The industryuniversity-government Triple Helix model introduced by Etzkowitz and Leydesdorff (1997) gives emphasis to both social and economic roles of the university. Conditions of innovation within this context can therefore only be fulfilled through the interactions among the three entities. Within the Triple Helix model, it is necessary for the university to have direct established linkages with industry so as to allow for maximum industrialization of knowledge. Therefore, a 'third mission' of the university is highlighted within the context of the university serving economic development apart from only teaching and research (Etzkowitz and Leydesdorff 2000).

Alternatively, Dasgupta and David (1994) argue that in the New Economics of Science, universities serve an innate function that focuses solely on education. Within this context, there is danger of the university-industry relationship becoming too close thereby harming a nation's scientific potential. Therefore, a suitable separation of labor between these two players is called for. However, since each country would have its own NIS where industry-university linkages take different forms while assuming various functions in a nation, then understanding NIS in the context of developed versus developing countries requires a 'contingent or context-specific' viewpoint of industryuniversity relationships (Eun et al. 2006).

Furthermore, in trying to understand technological growth and progress in nations, two paradigms emerge from the literature, the catch-up paradigm and the innovation paradigm (Wang 2007). The catch-up paradigm takes into account the late-industrializing country's technological learning. The state within this economy is considered possibly capable to lead the economy, adopting restrictive policies for controlling capital flows, and mobilizing savings domestically to enhance industrialization (Hobday 1995; Kim 1997). The state can in this sense adopt two approaches: firstly, through an aggressive pro-national champions policy, allocating scare resources, among a few domestic enterprises, while nurturing centralized industrial structures dependent upon economies of scale for their competitiveness; and secondly, through adopting a more decentralized approach, where domestic firms tend to grow smaller in size while depending on external resources for their technological competitiveness (Hobday 1995; Kim 1997).

The innovation paradigm on the other hand is mainly applicable to advanced economies. This paradigm focuses on generating and discovering 'frontier technologies' that are not yet in existence within the market. The state in this paradigm cannot play the leading role as it does not possess the necessary know-how to do so. Instead, it adopts the role of regulator to establish the required infrastructures to foster generation of new knowledge and technologies (Lundvall 1992; Eichengreen 2002; ADB Asian Development Bank 2003; Wang 2007). In addition, two interrelated factors have proved important to influencing the way political economies evolve from a catch-up economy to an innovation-based economy. This includes the state's approach to economic liberalization and the need for firms to pursue capital investment so as to keep up with technological innovation (Weiss 2003; Pirie 2005). 
However, despite the vast literature available on the subject matter, few studies have dealt with the issue of how economies like that of South Korea's (later referred in this study as 'Korea') have been transitioning from a catch-up-based to an innovation-based economy. Even more so, the evolving of universities from an ivory tower to an entrepreneurial university within the Korean NIS has often been ignored in such contexts. The aim of this pair-wise comparative case analysis of two Korean universities is to therefore arrive at key propositions concerning why and how Industry can initially play a key role in supporting the transitioning of the university from an ivory tower to an entrepreneurial format. This paper advances the Corporate Helix model to highlight the transitioning of Korea's innovation-based growth could be explained through the Corporate Helix Model (Cho 2008). In this model the university is acquired or established and then transformed into a corporate/entrepreneurial university by a firm before becoming an independent player in the triplex network relationship between university-industrygovernment.

The paper is divided as follows. The remainder of the 'Background' section offers a brief discussion of Korea's technological catch-up to innovation-based growth. Section 'Theoretical developments and conceptual model - the Corporate Helix model' discusses the theoretical basis of the Corporate Helix model, i.e., the double helix formation and the triplex network. Section 'Methods' discusses the transition of Pohang University of Science and Technology (POSTECH) (Cho 2008) and Sungkyungkwan University (SKKU) (Cho 2013) based on the Corporate Helix model within the context of Korea's evolving NIS environment. Section 'Results and discussion' highlights the divergent and convergent routes of both POSTECH and SKKU. Section 'Conclusions' concludes with some policy recommendations and offers suggestions for future research.

\section{South Korea's technological catch-up to innovation-based growth}

NIS encompasses the streams of information and technology among institutions, enterprises, and people that are integral to innovation processes at the national level (Yam et al. 2011). Korea still struggles with a fragile past in terms of its relations with its neighbors. Nonetheless, because of its history, it can be expected to entertain a national system of innovations (Park and Leydesdorff 2010). The development of both universities and industries nationally and internationally can be observed in recent decades. Also, a range of interventions have been undertaken by national governments to reinforce the knowledge base of innovations with regards to university-industry relations and to encourage the development of various sectors (Park and Leydesdorff 2010).

In the early 1990s, Korea's economy began to experience pressures of liberalization and technological upgrading (Kim 2000; Kong 2000). It can be observed that Korea developed competitive strengths in its technological catching-up and that this was due to the existing institutional arrangements before the 1990s. The Korean state's high-debt model nurtured a chaebol-dominated industrial structure during the former stage that led it to pursue scale-based technological development. The state's approach to economic liberalization and the firms' demand for capital for technological upgrading are the major factors that have underpinned the economic adjustment and pursuit of technological innovation in Korea (Wang 2007). 
In terms of Korea's high-debt and high-volume model of economic catching-up, before the 1990s, the state's strong leadership, the state-owned banking system, and the dominance of the chaebol in the industrial structure characterized economic development (Amsden 1989; Woo 1991; Fields 1995; Kim 1998; Kong 2000). To promote 'big push' industrialization, the Korean state had to mobilize financial resources via domestic and foreign savings to encourage the chaebol via arbitration of state-owned banks. This led to the chaebol being an outcome of the Korean state's big push strategy which further resulted in the economy being dominated by a small group of chaebols (Fields 1995; Woo 1991). Eventually, the chaebol was able to develop a high-debt-high-growth business model while assimilating existing technologies rapidly due to the state's unrestricted supply of capital. The chaebol eventually replaced the state as the major driver for integrating and augmenting technologies (Kim 1997). Korea's semiconductor industry, for example, modified Japanese production techniques for standardizing commodity products into a low-cost strategy. Despite reliance on equipment from countries like the USA and Japan, the development of the industry's technological capability resulted from the chaebol's own efforts in research and development and learning activities (Wang 2007).

Korea evolved into a neoliberal regime with economies of scale while paving the way for innovation (Kong 2000). Evolution of political democratization and economic liberalization emerged in the early 1990s through the 'New Economic Plan'. The chaebol's political power had also increased as a result with a focus on global expansion. The neoliberal approach allowed chaebols to expand which further aggravated their debt-to-equity ratios owing to increasing demand for capital, majority of which was borrowed from abroad. This led Korea into the 1997 financial crisis owing to a lack of matching structural and regulatory reforms (Wade and Veneroso 1998; Chang et al. 1998; Weiss 2000).

Further reforms took place post the 1997 financial crises, which included completion of trade and financial liberalization, privatization and corporate governance reform, and labor-market deregulation (Hundt 2005; Wang 2007). This led to the increase of the state's authority while decreasing the chaebol's power. An emphasis was put on economic globalism as opposed to economic nationalism, and from the chaebol's outward globalization to a focus on transnationalism following the liberalization policy. The Korean government's key role had thus turned to encouraging technological development through engaging in key research and development projects, with a focus on the top few chaebols which continue to dominate the industrial structure via the Schumpeterian scale economies (Wang 2007; Eom and Lee 2010).

Nonetheless, amidst the "twin dominance" of big business (i.e., Chaebols) and the government, the role of universities appeared to be relatively weak (Kim 1993; Lim 2006; Choi et al. 2007; Eom and Lee 2010). OECD (2008) reported that universities and industries employ around $70 \%$ and $20 \%$ of doctorates in Korea respectively. However, both universities and industries have managed to conduct only $10 \%$ and $77 \%$ of research in Korea respectively. Therefore, one of the great weaknesses of the Korean NIS was attributed to the lack of interaction between university and industry, which was due to the nature of Korean universities as being teaching-oriented. However, since the 1990s, research had been given a growing priority in Korean universities (Kim 1993). The remaining sections of this paper highlight, through the cases of POSTECH and SKKU, key relationship characteristics between industry-university-government that have evolved over time to give way to the 
emergence of the entrepreneurial university, within the Korea NIS, leading it from technological catch-up to innovation-based growth.

\section{Theoretical developments and conceptual model - the Corporate Helix model}

The changing environment for the university in Korea was strongly influenced by the changing environment of the Korean Government's university policies (Kwon 2009). For example, the founding of the Korean Advanced Institute of Science and Technology (KAIST) was the first public research university established by the Korean government with the assistance of American policymakers in 1971 to enable an orientation towards science- and engineering-based research to be integrated into the Korean NIS. This perhaps reflects one among other key events relevant to the changing environment of the Korean Government's university policies. The changing environment included a strong regulation of the country's education system to enable economic takeoff between the 1960s and mid-1970s and liberalization and globalization since the 1990s (Lee et al. 1998).

Since 1980 an implementation of a series of unique educational system reforms has taken place. This included the huge expansion of the university and the loosening of the former strong regulatory environment of universities. The number of students in nontechnological disciplines like humanities and social sciences increased in comparison to the science and engineering disciplines that were emphasized in the prior period through vocational training (Kim and Lee 2006). By the end of the 1970s the first explosion in the demand for higher education as a result of the strong regulation policy, which was based on a fixed number of students, can be observed (Lee 2006; Kwon 2009). The growth in the national economy allowed households to better afford tuition fees, and this in turn also led the industry to demand for more qualified candidates.

Furthermore, during the 1990s democratization accelerated the deregulation of education policy, making it easier to establish higher education institutions. Some of the reforms included the abolition of the quota system for higher education institutions in 1995 which allowed for the increase in the numbers of higher education institutions. This included small- and medium-sized private universities in regional areas as well as new forms of universities, such as graduate schools without undergraduate students, as well as online universities for enabling distance learning (Kwon 2009). This further allowed large private universities in Seoul to establish a dozen local autonomous campuses which can be considered as the second explosion in the number of universities and students enrolled.

Moreover, the Triple Helix community in Korea has seen some key trends over the past decades. Post 1997 to 1998 Asian financial crises, the new Korean government programs were geared towards differentiation between three sectors of the research system (Park and Leydesdorff 2010). Firstly, academia was encouraged to grow according to the existing international criteria of publications and citations. Secondly, the industry was no longer entwined with the national knowledge base. Thirdly, incentivizing project-based system in public sector research was established to direct research outcomes into commercially feasible innovations and technologies. Therefore, for the university, this policy accompanied an ongoing trend to place emphasis on international publishing by adapting hiring and promotion policies to such core incentives.

Also, as a result of this differentiation, Triple Helix relations became less central not only to policy making but also to the Korean innovation system dynamics itself. Such a synergy 
in Triple Helix relations appears to have crumbled since 1998, and the Korean government has thus been left out at the national level of integration between university, industry and government (Park and Leydesdorff 2010). This phenomenon seems to have emerged as a result of the Korean government's and universities' emphasis on publication performance in funding allocations, grants, faculty recruitment, promotion, and tenure. Such factors seem to have discouraged collaboration between the three institutional spheres of the Triple Helix dynamics (Park and Leydesdorff 2010). This phenomenon further serves as a crucial back drop for the current study to allow for retracing the relationship dynamics between university-industry-government in the context of the role of industries in the technological catch-up of Korea to innovation-based growth through a Corporate Helix modeling.

The Corporate Helix model and the Triple Helix model share similarities in that the three entities composed of university-industry-government are entwined to each other to allow for technological catch-up for innovation-based growth within an economic environment. The key difference between the two models is the university. In the Corporate Helix model, the university does not have capabilities to take part in technological catch-up endeavors by being an independent player through its interactions with industry. However, the model postulates that the university is eventually transformed into an entrepreneurial university through the steering efforts of the industry (corporation). The initial key player is therefore the firm that maintains this steering role until the relationship dynamics between university-industry-government and the existing internal and external environments becomes conducive to be replaced by the Triple Helix relationship where the university functions entrepreneurially.

The university in the Corporate Helix relationship is initially acquired or established (including through strategic alliances with specific academic sectors) by the industry who invests to transform the university into a competitive entity. Within the Corporate Helix model, the industry can encompass both private and public corporations. To understand the successful formation of the Corporate Helix relationship, two subprocesses need to be considered, namely, the sequential formation of the double helix and then the triplex networks.

\section{The double helix formation}

During the double helix formation, the university and industry interact closely. This close interaction is enabled through organizational adaptation that allows the university to become more complementary to the corporation. The organizational adaptation that occurs between the ivory tower and corporation is called 'corporate-induced fit'. What is then integrated into academia is the catalyzing process by capital expenditures and comparative advantages of the corporation which later enables a complementary relationship between the university and corporation. Since at the initial stages of the double helix formation multiple weak interactions exist, the corporation must bring to the table attractive investments and a support system enabling optimization of the binding capacity during the double helix formation stage. The university will then be required to undertake organizational restructuring to integrate entrepreneurship and financial investment.

The double helix formation therefore allows for the conversion of an academic steady state to an academic entrepreneurship state. The organizational change and adaption that follows then permit continuous and flexible transformation to occur. This 
conversion could be multi-dimensional and complex which would permit the university to engage with more variables and with added complexity in both internal and external environments. Through successful formation of the double helix, the university, once an ivory tower, now possesses the capacity to establish strategies for collaborating with industry and government. Also, the university can now plan how best to capitalize on emerging opportunities while creating an efficient campus where productivity of faculty and administrators gradually advances with utmost impact.

It must be noted that during the incubation period of the double helix formation, strategic and specific academic reforms are essential to reshaping the university. When an organization consists of multi-academic disciplines, a strategic reform of one department as a result of an alliance with a corporation could impact the physiology of other academic areas leading to wide-ranging new alliances. A key strategic alliance between one department and the corporation would be necessary to disperse a binding affinity to other academic fields in the initial stage of the double helix formation, since some academic fields demonstrate greater affinity with the corporation. For example an engineering department can form an initial strategic alliance with a corporation wishing to strengthen its pool of research scientists in science and technology for enhanced innovation processes. Both university and corporation are thus held together through recognition of each other's deficiencies and complementarities. The university requires capital investment and entrepreneurship from the corporation which allows for new knowledge discovery for technological innovation. This in turn enables the university to have a complementary role with the industry while enhancing its usefulness, doubling its benefits and minimizing diminishing knowledge.

The university eventually becomes recognized as a knowledge generator by the corporation during the double helix formation. Since knowledge is virtually unlimited in its accessibility, inexhaustible in its availability, and unconstrained by time, it can therefore be extended in the range of its usefulness and grow in scope while increasing in refinement if the distance between the university and industry becomes closer. The university can then encompass scientific, technological, innovative, and economic developments in the long run with the industry. It is at the double helix formation stage that the university finds itself immersed in extensive transformations in governance, organizational behavior, and performance measurement to enable it to become a competitive knowledge provider. It is now able to add new specializations and accommodate to its changing role allowing it to address new challenges at relatively low costs. The corporate university thus begins to play an ever decisive role in the society.

Ultimately, the newly formed alliance between university and industry enables pooling of research opportunities. Also, apart from serving as an alternative to the limited public funding witnessed in developing countries, such an alliance revitalizes the intellectual life in the university. This is because corporate entrepreneurship infuses real societal needs while contributing state-of-the-art technology to free the existing confines of academe. The previous challenges for the university thus become lessened thereby allowing easier entry into the Triple Helix network.

\section{The triplex network}

The triplex network follows the double helix formation. At this stage the corporate university demonstrates capabilities to participate in the Triple Helix network with industry and 
government for encouraging technological innovation and economic development. In this relationship triad, the university is still relatively dependent on the corporation yet can function autonomously to allow for the hybridization into the triplex with industry and government. The three entities can now move in common direction to drive a knowledgebased economy as a system of innovation. The university now embodies a key role in the triad, steering on its own while contributing towards technological catch-up endeavors to innovation-based growth.

The foremost function of the corporate university, aside from generating new knowledge within the triplex network, then also encompasses the integration of knowledge in the business sector where there is a knowledge overflow. Since knowledge is always being aggregated, integration of knowledge to its users by the university with industry and government becomes the biggest challenge. The triplex network thus allows for the realization of this key step for technological catch-up. Partnerships then become a valuable means of getting the most. Partnership of the university with industry is strengthened with the double helix formation while this strength stretches out to the government in the triplex network.

The triplex network can thus be considered as an effective form of corporative partnership enabling quick transmission and commercialization of knowledge. This sort of partnership becomes more predominant as a way for the university to leverage corporate and national funds. Industry is also able to capture research discoveries along with establishing in-house expertise. In the triplex network, a corporation demonstrates capabilities in the translation of scientific discoveries into products, ideas, and other developments by being an active participant. It focuses its research efforts on technologies that are close to the market. Both university and industry are then encouraged by the government in the triplex network to focus on long-term basic research through extending R\&D tax credit permanently while eliminating encumbering regulations that inhibit joint-venture and joininnovation endeavors between the university and industry.

Symbiotic relationships rewarding to the university-industry-government triad can consequently be achieved in the triplex network. This partnership and collaboration triad becomes a crucial element in the technology transfer process from university to industry. The triplex thus draws together the efforts of academic, government, and industry while allowing for technological catch-up to innovation-based growth. The government eventually steps up its efforts in promoting the development of high-tech industries through supporting the university and through interacting with industry. The government also encourages industry to undertake scientific and engineering discoveries for the market through intellectual property protection. It has responsibility to make the outcomes of university-industry joint-ventures broadly available. Emergence of the corporate/entrepreneurial university in developing economies through the Corporate Helix model can thus, in time, allow such economies to achieve technological catch-up for innovation-based growth.

\section{Methods}

\section{Catch-up to innovation-based growth- the cases of POSTECH and SKKU}

Chaebols such as Samsung, Hyundai, LG, and Daewoo became key players in driving the economic development of Korea over the last decades. As a result, through its 
industry, Korea had experienced progress in technological innovation. Research and development in Korea had seen aggressive investments over the last 10 years while augmenting technological and scientific competitiveness. Nonetheless, despite such endeavors, Korea appeared to be weak in terms of knowledge production capabilities. In order to account for such differences between high R\&D/GDP ratio and low capabilities in knowledge production, understanding the role of universities within such dynamics become crucial (Cho 2008).

The weak competitiveness of the Korean universities in the fields of science and technology was due to the lack of a competitive environment among faculty members. Also, the lack of funds and facilities resulted in the inability of universities to provide competitive infrastructures to maximize professors' research (Cho 2008). Moreover, industry and government had proven to be the only key players in driving technological innovation and economic development of Korea for the last half century This is a result of the lack of entrepreneurial knowledge generating capabilities of the majority of universities in Korea.

Industry and government of Korea had in time recognized the significance and impact that universities could have in the progress of the economy and understood that without augmenting competitiveness of universities, then national competitiveness could not be enhanced. However, since universities in South Korea could not serve an entrepreneurial role, as the Triple Helix model posits, they could not function as strategic partners with industry to generate and commercialize knowledge (Cho 2008).

Therefore, understanding the technological catch-up process of Korea, and perhaps of other economies, during their developing stage to innovation-based growth cannot be plausibly done via the Triple Helix model owing to the absence of entrepreneurial universities. In the context of developing economies, it could take considerable time before a university demonstrates independence in interacting with industry and government. The Corporate Helix model therefore compensates for this loophole in the interactions between university-industry-government in ensuring technological catch-up where an entrepreneurial university is lacking. Two cases shed light on the technological catch-up of South Korea to innovation-based growth without the entrepreneurial university: the cases of POSTECH and SKKU (refer to Table 1).

\section{Results and discussion}

\section{Double helix formation of POSTECH and SKKU}

In order to understand the evolutionary cycle of the university within the Corporate Helix model during the double helix formation, three stages are proposed: the concession stage, the inauguration stage, and the assimilation stage.

\section{The concession stage}

Pohang Steel Company POSCO had established and solely funded POSTECH University, modeled after the California Institute of Technology in 1986. The Caltech model served as an appropriate model for replication owing to its strong emphasis on science and engineering, its relatively small campus size, and its short history of establishment - key factors that could deliver POSTECH's vision of eventually becoming the national pride and symbol of science and technology innovation. This event reflected the emergence of an evolutionary era of universities in Korea. There was a growing realization within the key 
Table 1 Validity and reliability criteria and treatments within the study

\begin{tabular}{|c|c|c|}
\hline $\begin{array}{l}\text { Validity/reliability } \\
\text { criteria }\end{array}$ & Measure utilized & Treatment addressed \\
\hline \multirow[t]{2}{*}{ Internal validity } & $\begin{array}{l}\text { Research framework derived } \\
\text { from literature }\end{array}$ & $\begin{array}{l}\text { The underlying framework for the study that } \\
\text { allowed for the exploration and classification } \\
\text { of the Corporate Helix model, as well as the } \\
\text { resulting propositions for the model, is based } \\
\text { on the triple helix studies by Etzkowitz and } \\
\text { Leydesdorff (1997), specifically, Universities and } \\
\text { the Global Knowledge Economy: A Triple Helix } \\
\text { of University-Industry-Government Relations }\end{array}$ \\
\hline & Pattern matching & $\begin{array}{l}\text { Observed patterns for the case on SKKU-Samsung } \\
\text { were compared to patterns established in a } \\
\text { previous Corporate Helix study on POSTECH-POSCO }\end{array}$ \\
\hline \multirow[t]{2}{*}{ Construct validity } & Data triangulation & $\begin{array}{l}\text { Annual reports, bulletins, newsletters, newspaper } \\
\text { articles, website information, and online documents } \\
\text { were screened. Follow-up interviews were conducted } \\
\text { with key respondents from both companies and } \\
\text { universities to cross-verify specific material }\end{array}$ \\
\hline & Explanation of data analysis & $\begin{array}{l}\text { A pair-wise case approach was applied so as to } \\
\text { develop conclusions and insights. A comparative } \\
\text { method in data analysis procedures was undertaken } \\
\text { to allow for deriving propositions that can be traced }\end{array}$ \\
\hline \multirow[t]{2}{*}{ External validity } & Cross-case analysis & $\begin{array}{l}\text { Pair-wise cross-case analysis was conducted between } \\
\text { POSTECH-POSCO and SKKU-Samsung, including } \\
\text { government bodies from South Korea, with multiple } \\
\text { informants from different levels of the Industry, } \\
\text { University, and Government to further allow for } \\
\text { methodical generalization of the Corporate Helix case }\end{array}$ \\
\hline & Rationale for case study selection & $\begin{array}{l}\text { The selection of POSTECH-POSCO and SKKU-Samsung, } \\
\text { including the Ministry of Education of South Korea, } \\
\text { accounted for conditions proposed by the Corporate } \\
\text { Helix model. Selection of POSTECH-POSCO and } \\
\text { SKKU-Samsung cases allowed for addressing the } \\
\text { double helix formation stage between University and } \\
\text { Industry of the Corporate Helix model. Selection of } \\
\text { the Ministry of Education allowed for addressing the } \\
\text { triplex network stage with the Government after } \\
\text { double helix formation }\end{array}$ \\
\hline \multirow[t]{2}{*}{ Reliability } & Case study database & $\begin{array}{l}\text { Case study notes, documents, and narratives were } \\
\text { collected during the study to enable future replication } \\
\text { of the model for the cases of Hyundai and LG which } \\
\text { are currently being investigated by the author }\end{array}$ \\
\hline & $\begin{array}{l}\text { Actual organization/company/ } \\
\text { institute names provided }\end{array}$ & $\begin{array}{l}\text { Actual names of companies, universities, and } \\
\text { government bodies on which the study is presented } \\
\text { are provided }\end{array}$ \\
\hline
\end{tabular}

leadership of POSCO that education can drive the necessary social reforms (Innace and Dress 1992). This could further enable the growth and development of the world's best possible research-oriented university that can provide the necessary manpower to enable Korea's strengthened position in the international community. There was recognition of the need to create technologies and applications as part of an initial push to develop the nation. POSTECH's leadership acknowledged that only through originality, innovation, and ingenuity can the intellect and the university be driven towards the quest for knowledge and new discoveries (Cho 2008).

In contrast to POSTECH, SKKU, which was considered the most traditional ivory tower university, was acquired by Samsung Corporation in 1996. Prior to the acquisition, SKKU had been stagnant during the last decade when the traditional education system of Korea faced challenges inside and outside the nation as a result of 
globalization (Cho 2013). The community of SKKU recognized that a strategic plan for survival was required in such a changing environment. Samsung did not initially view SKKU as a strategic partner. It had assisted SKKU towards becoming an independent entity through the Triple Helix model path. However, over time, given SKKU's need for a strategic and sustainable plan for survival and for Samsung's Medical Center's (established in 1982) need for affiliation with biomedical research for its own sustainability (as advancing medical treatments need to be supplemented by biomedical scientific research), a consensus for corporation acquisition of SKKU was led by SKKU (Cho 2013).

Prior to 1996 the initial dialog between SKKU and Samsung during the acquisition stage did not fare well as a result of differences in each's scope of interests. Samsung did not initially view SKKU as a strategic partner. Samsung had been supporting more than 25 universities in the nation with funding for over twenty years in Korea through the 'Samsung Lee Kun Hee Foundation. Samsung was not interested in intensive investment into any single university such as SKKU. Consensus between the two had not been realized until the proposal of the establishment of the medical school for Samsung and the creation and/or reinforcement of programs related to technological innovations, by SKKU's President Bum Jin Jung. Within SKKU, there was already mutual understanding among faculty members that SKKU would require large pools of financial investments to replace depreciating facilities, to enroll talented students and recruit and retain distinguished faculties in diverse areas.

Nonetheless, the inclusion of the establishment of the medical school for Samsung by SKKU's key leadership in the acquisition package proved timely and attractive to both Samsung and SKKU. Also included were propositions for capitalizing on SKKU's pool of research scientists and faculty members in science and technology that could tremendously contribute to Samsung's innovation process. Furthermore, SKKU's community also looked forward to Samsung undertaking key managerial roles as a result of the university's depletion in internal capacity to raise the university's competitiveness and comparative advantage (Cho 2013). This observation of the initial stages of the double helix formation between University and Industry leads us to the first proposition:

Proposition 1: Double helix formation between University and Industry is initiated through a two-way flexible approach, i.e., the establishment of the University or the acquisition of the University.

\section{The inauguration stage}

The establishment of POSTECH was made possible through devotion of key leadership. In the summer of 1986, the Ministry of Education permitted the establishment of POSTECH. POSTECH's president began recruitment of top faculties among active Korean professors in the USA and Europe. Around 200 distinguished Korean scientists were recruited in ten different Science and Technology departments. Majority of the recruits held specialized doctoral degrees and were the ones who returned to Korea to continue research at POSTECH after years of lecturing at major universities in the USA and abroad. Faculties in POSTECH were awarded one of the highest salaries in the nation and were provided with full support of laboratories, equipments, research funds, and free housing. POSTECH faculty proved a dedicated role in assisting Korea to pursue self-sufficiency (Cho 2008). 
In 1996 Samsung decided to acquire SKKU through a joint-venture. A proposal had been submitted to the Ministry of Education for establishment of a medical school by SKKU. During this critical stage, the role and support of the government proved significant since the Korean community exhibited a rather conservative outlook regarding academia that supported the underlying principles of the New Economics of Science view, i.e., academia should stay separated from the private sector. Nonetheless, the government endorsed the proposal and assisted in facilitating the alliance between SKKU and Samsung while providing administrative support to expedite the hybridization between academia and corporation (Cho 2013). Thus, the key role of the Korean government observed during the double helix formation stage leads to the next proposition:

Proposition 2: University and Industry will be better able to integrate double helix formation efforts for the purpose of technological catch-up through the initial facilitation and support of the national government.

\section{The assimilation stage}

POSCO and POSTECH key leadership acknowledged that a new research institute would be required and needed to be in proximity to POSTECH for knowledge application and for accelerating the testing process of the applicability of scientific discovery from the university. The Research Institute of Industrial Science and Technology (RIST) was consequently established in March 1987 (Cho 2008). Activities at RIST ranged from short-term projects for industry to future-oriented projects for the development of strategic technology. Studies encompassed areas of iron and steel technology, general science and engineering, advanced materials, management, and economics (Innace and Dress 1992). An advanced science and technology manpower base was eventually secured by RIST.

Moreover, aside from RIST, POSTECH also hosted the Pohang Accelerator Laboratory (a national users' facility and the only synchrotron light source in Korea). This allowed for the analysis of the atomic structure and drew the attention of researchers worldwide. The installation of the synchrotron light source became Korea's turning point in scientific development. POSTECH learned to become engaged in research and development through supporting over 60 research centers within its campus. As a result of the availability of the research potential and resource-sharing at POSTECH, the university was able to atract top professors and researchers from around the world (Cho 2008).

In 1994, POSCO's newly appointed senior management established the POSTECH foundation. As a result USD 140 million of funds had been invested into POSTECH. Eventually, additional endowment was provided to POSTECH under the new industry-academy alliance concept. Within this arrangement POSCO supports research that POSTECH conducts while earning the right to review all scientific findings and the right to commercialize (Cho 2008). There was also endorsed profit-sharing agreement from patents between POSCO and POSTECH. In 2000 a USD 300-million endowment was released by POSCO out of which USD 35 million was devoted to the construction of the POSTECH Biotech Centre. Aside from RIST, the Information Science Centre and the Graduate School of Iron and Steel Technology (GSIST) were also established at POSTECH by POSCO which allowed for similar strategic alliance. 
A triadic relationship among academic, research, and industry had therefore been pursued in various areas since the foundation of POSTECH by POSCO. About USD 2 billion in total had been invested into POSTECH by POSCO since its foundation. Two percent of POSCO's R\&D budget had been set aside annually as research fund for POSTECH where research is jointly carried out by RIST and the university's faculty members who, in turn, provide technological support to the company (Innace and Dress 1992). The triad functioned to not only share profits with society but to also provide basic applied research (Innace and Dress 1992).

Like POSTECH, several ongoing organizational assimilations occurred after the Samsung-SKKU joint-venture. Between 1997 and 1998, SKKU established a medical school, a medical research center, a semiconductor manufacturing R\&D center, a department of computer education, and a graduate school of business. The Samsung and SKKU strategic efforts also expanded to restructure the campus through establishment of the college of medicine, the graduate school of design, and the graduate school of business administration. A graduate programme at Samsung Technology Center and partnership with Samsung Art \& Design Institute was also established. During the period of 1999 to 2000, SKKU constructed medical buildings and established partnership with Samsung Stock Exchange and Samsung Electronics/Semiconductor. Between 2002 and 2006, SKKU then partnered with Samsung Economic Research Institute and created the department of mobile phones through a joint graduate program with Samsung (Cho 2013).

From 2004 to 2009, the law school, the international house, Samsung library, and international hall were constructed. Also, the humanities and social science campus in Seoul and the natural sciences campus in Suwon had begun operations, placing natural sciences on an equal footing with its strong foundation in humanities. Additionally, during this period the 'Core Initiative Programmes' had strategically been funded by Samsung for each campus (Cho 2013). Samsung eventually extended its funding support towards the humanities and liberal arts, as well as science, engineering and business at SKKU. Samsung had also introduced a comparative performance based salary system. This was driven by productivity and an enabling environment for faculties to carry out research activities through availability of research funds and equipment.

Additionally, Samsung had also offered full scholarships and research funds for students at the medical school and departments of semiconductor/electronics, and faculties. This led engineering faculties to get engaged in the generation of innovative products with Samsung's research scientists while engineering graduates further received employment with Samsung. Additionally, the Samsung Economic Research Institute (SERI), which is the largest private think tank in the nation, became a resource for SKKU, allowing it to develop strategies for ongoing improvements in the effectiveness of human resources and capital. SERI also participated in SKKU's strategic planning which provided the university with the required instincts to sense its surrounding environment that is constantly changing and to embrace adaptation while developing greater integration, quality, and stronger integrity by capitalizing on their available strengths (Cho 2013).

The establishment of SKKU's governance infrastructure also resulted in the restructuring of old financial frameworks and systems. Qualified faculty and staff were carefully selected by SKKU while professional administrative cadres were recruited (Cho 2013). Aside from the USD 50 to 100 million investments in SKKU each year by Samsung since 1997, assimilation of the Samsung-SKKU joint-venture was also successful through the 
voluntary engagement and participation of faculty members in SKKU's restructuring process. This was paramount among the university community and this led to the transformation process of SKKU into an entrepreneurial university.

Assimilation within SKKU was successful for two key reasons. Firstly, Samsung did not exercise academic capitalism to reshape the university to become entrepreneurial. To achieve the best intellectual outcomes, Samsung helped the faculty pursue the research field of their choice and ensured that corporate intervention did not distort the judgments and actions of the professors when they selected specific research directions. Samsung also did its best not to threaten the traditional integrity of the university. Samsung tried to maintain institutional autonomy, lively faculty independence, and vigorous academic freedom. Samsung and SKKU's President tried to develop responsible, effective, and balanced governance, leadership, and management as it entered the new era. Secondly, self-motivation was eventually voluntarily mobilized among the faculty. They realized that it was absolutely essential for SKKU to address its environment, its programs, and its future in a more systemic way if they were to grow in quality and move into the academic fields of tomorrow. The faculty's reaction was cautious but supportive. These observations from the assimilation stages of both POSTECH and SKKU lead to the following proposition:

Proposition 3: Successful double helix formation can be realized only after substantial realignment of structures and resources by the University and Industry directed at serving a common goal for technological catch-up within a Nation Innovation System.

\section{Triplex formation with the government of South Korea}

In terms of the SKKU and POSTECH affiliation with the existing government during their evolutionary process to becoming entrepreneurial universities, both received support and assistance from government. The establishment of POSTECH was made possible through the endorsement of the ministry of education. Also, the government had played a somewhat indirect role within the POSTECH triad with industry and government. For example, the then Korean president Kim Young Sam had appointed Kim Man Jae, the former Korean Vice Premier, as chairman of POSCO once previously chaired by Park Tae Jun (POSCO's previous chairman) who had left (Cho 2008). Through this strategic industry-academy alliance with close involvement from the government, POSCO was then able to provide POSTECH with endowments that enabled the university to evolve into an autonomous yet independent entity while being recognized as a partner of industry.

The role of the government also proved crucial to the transformation of SKKU into an entrepreneurial university. The government supported the acquisition of SKKU by Samsung amidst growing controversies owing to the conservative views of the larger Korean community. The government provided full administrative support, while the ministry of education facilitated the interaction between Samsung and SKKU through removal and shrinking the legal barriers related to the acquisition of a university by a corporation (Cho 2013). Even though the government is not directly engaged during the double helix formation, its role is crucial to offer the necessary support to assist the transformation of the ivory tower into an entrepreneurial university. The Corporate Helix relationship thus demonstrates the necessity of the country, state, or local governments to 
support key areas of the university-industry alliance process. This will in turn allow for the strategic transformation into corporate departments, college, or university that enables technological-catch up of the nation to innovation-based growth.

\section{Divergent and convergent routes of POSTECH and SKKU}

Though the cases of POSTECH and SKKU demonstrate divergent routes in their technological catch-up during the double helix formation stage (i.e., the former was established, the latter was acquired), there is a convergence in outcomes (see Figure 1). Ever since its establishment in 1986, POSTECH has endeavored to achieve excellence. POSTECH eventually became recognized as a top national academic institution offering one of the best Science and Technology programs within the Asian region in a short time. This served as a key to attract the brightest students and scholars to the Pohang area (Innace and Dress 1992; Cho 2008). Additionally, through competitive standards for promotion of its faculty and the development of its technical know-how and expertise, POSTECH was able to assist Korea in reversing its brain-drain (Innace and Dress 1992; Cho 2008).

POSTECH was able to develop a wide range of innovative technologies and applications through seeking synergies that were available between industry and academia. This led to the establishment of the POSTECH Biotech Centre and strategic biobusiness partnership with POSCO. POSTECH has grown to lead Korean biotech research, bringing forth its discoveries to the market as it establishes itself in the hitech sector. POSTECH also extended its program outreach to MBA students while investing USD 50 million to the POSCO bio-venture business in San Diego, USA, giving it promising lucrative stake in the bio-venture industry and a valuable network for potential future ventures. The Pohang Techno Park was also completed in 2000 to facilitate technology transfer and to enhance the reputation of Korea and Pohang as a technological center. Through the relationship triad POSTECH shares with industry and government, POSTECH has been committed to launching Korea into the forefront of innovative science and technology in the twenty-first century while supporting POSCO in maintaining its competitive edge (Innace and Dress 1992; Cho 2008).

The successful acquisition of SKKU by Samsung, through a hands-off approach and voluntary mobilization of the faculty at the initial stages of the double helix formation, enabled SKKU to strategize in confronting and dealing with its challenging realities. SKKU standards thus improved while university progress was generated. Through innovation management techniques, such as the seven Sigma quality improvement and an active internationalization program, the academic standing of SKKU grew domestically and internationally ever since its joint-venture with Samsung in 1996.

SKKU was also able to develop its core research areas, one of them focused on graphene technology where SKKU along with Samsung was filing the highest number of graphenerelated patents in the world. The newly established SKKU department of Energy Science was also able to initiate research in Korea's basic science area during the next ten years. This allowed SKKU to also grow and progress to become a world-leading research institute in basic sciences. Also, through the support and collaboration of Samsung, SKKU was able to enter the nano-structural physics field while also developing a world-class center of research and teaching at the SKKU School of Pharmacy (Cho 2013). Therefore, as a result of intensive investment from Samsung for almost over two decades, SKKU has become one of the top schools in Korea, achieving excellence through its school of 


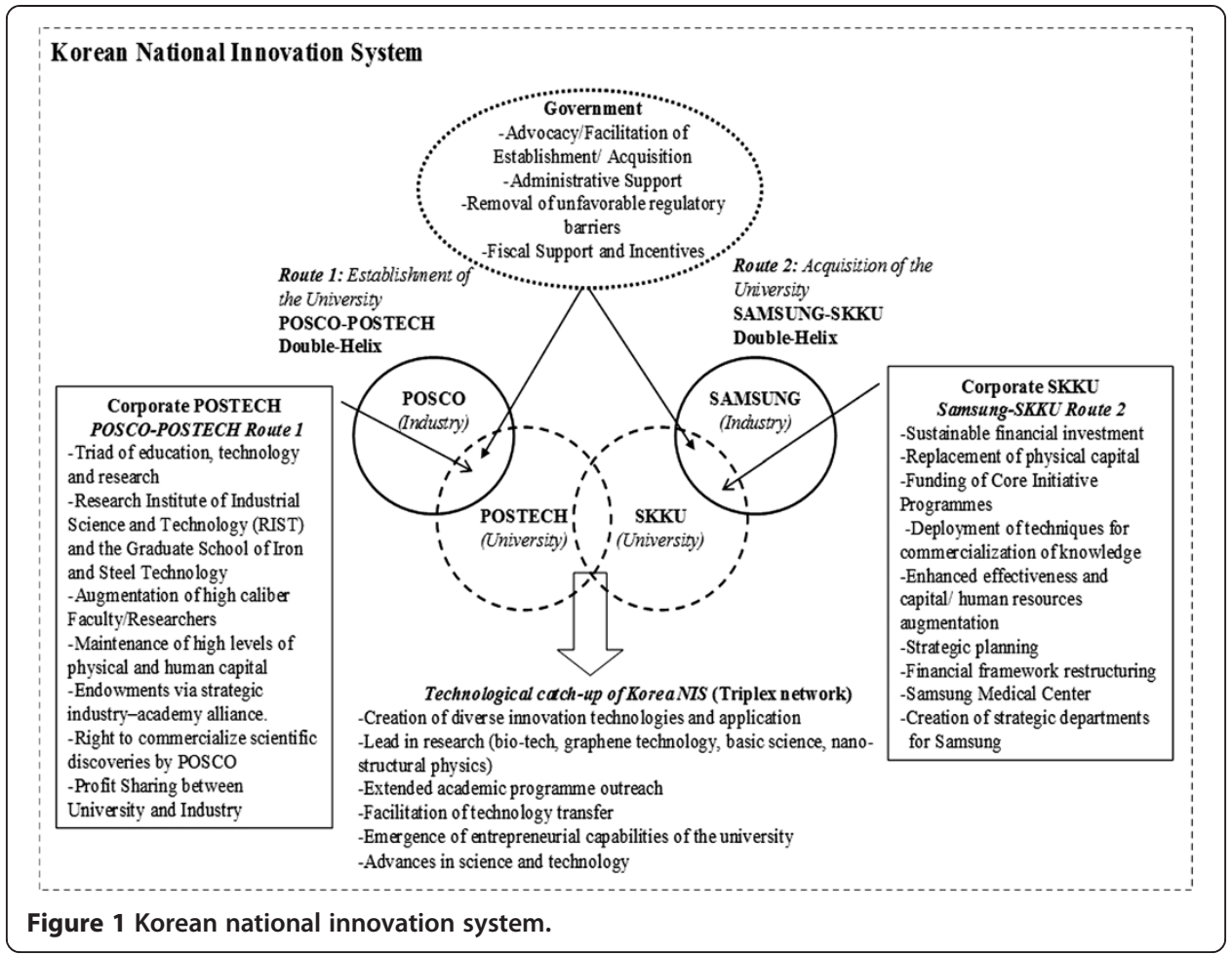

medicine, engineering, pharmacy and business. It was transformed from an ivory tower, isolated from society, to becoming an entrepreneurial university through close interaction with the industry and government so as to cultivate the efficacy of Korea's NIS. Therefore, based on the divergent and convergent routes of POSTECH and SKKU, the following two additional propositions can be offered:

Proposition 4: Universities can adopt an entrepreneurial role for technological catch-up after being transformed by the Industry to perform knowledge generating functions within knowledge-based economies.

Proposition 5: Successful emergence of the university as an entrepreneurial university takes place in a three-stage hierarchical model incorporating the concession stage, inauguration stage, and assimilation stage.

\section{Conclusions}

This paper offered discussion on the cases of POSTECH and SKKU to highlight the role of universities in the transitioning of the economy of Korea from technological catch-up to innovation based growth. The evolutionary cycle of the university from an ivory tower to an entrepreneurial university within the Korean NIS was illustrated through the Corporate Helix model. In order to permit the participation of the university in technological catch-up, it should be equipped with competitive factors of production like facilities, professors, and students that can enable maximization of production efficiency. However, in some developing countries, such resources are not available; therefore, universities are unable to create knowledge that can eventually be commercialized by the industry. The Corporate Helix model takes into account the 
university which lacks the capability to become entrepreneurial. Such a university is established or acquired by industry and through this partnership it undergoes transformation to become an entrepreneurial university. The cases of POSTECH and SKKU illustrates that such a strategy is possible.

A knowledge economy had started to emerge in Korea as a result of this new configuration which also placed the university at the center of the country's innovation-based growth. Therefore, the Corporate Helix model of university-industry-government relations is likely to become a key component for national or multi-national innovation strategies in economies where private or public corporations play an initial key role for the emergence of entrepreneurial universities. It is evident, from the cases of POSTECH and SKKU, that in order to transform universities to perform knowledge-generating functions within knowledge-based economies, replacement of physical capital, modification of curricular and pedagogy, and creation of wider institutional ecology, including better funding, become indispensable.

Governments therefore also need to adopt a catalytic and pro-active role for promoting the formation of the new innovative flow that the Corporate Helix model enables. Unnecessary regulatory barriers need to be lifted. Also, administrative support and incentives through mechanisms like tax benefits should also be considered as a way to encourage a firm's establishing or acquisition of a university. This will enable governments to form closer relationships with both the university and industry to achieve technological catch-up for the nation while enhancing the likelihood of collaborative innovation through a strengthened NIS.

\section{Discussion for future research}

In order to yield valid theoretical and policy implications, much is left to be explored concerning the technological catch-up of the university, industry, and government within the Corporate Helix model for innovation-based growth. Future studies should consider an in-depth exploration of the emerging technological innovation capabilities as a result of the double helix formation stage. A new era of intense global competition can be observed among industries worldwide as a result of developments of the World Trade Organization and other international trade agreements (Dierickx and Cool 1989; Guan 2002; Yam et al. 2004). This has led to an ongoing need to adapt, develop, and innovate to augment organization excellence. Therefore, in order to facilitate and support technological innovation strategies, there is a growing reliance on an all-inclusive set of organizational characteristics or technological innovation capabilities (TICs) (Burgelman et al. 2004).

The building of technological capability in Korea demonstrated phenomenal growth (Kim 1999). Implications from Kim's (1999) study offer some evidence of external and internal elements that could have influenced the process of building technological capability in Korea. There was a need for public technology policies and private technology strategies to evolve over time to adjust to shifts in the market and technology environment. Also, export promotion proved to be an effective public policy instrument for generating competitive stimulus among firms to accelerate technological learning, while rapid increase in education at the mature technology stage allowed firms to obtain adequate existing knowledge bases for technological learning. 
Moreover, there appeared to be a liberal policy on brain-drain that in the long run enabled scientists to eventually return to Korea to play a key role in discovering intermediate and emerging technologies (Kim 1999). Furthermore, three elements proved complementary in building a high tacit-knowledge base which is a key prerequisite to effective technological learning, namely, (1) the recruitment of high-caliber human resources, (2) foreign technology transfer, and (3) learning by research through in-house R\&D. Moreover, Korea's technology transfer strategy evolved over time, adjusting as industrialization progressed. Finally, intensity in effort proved to be another prerequisite for building technological capability since one of the most effective ways to intensify effort at the individual and organizational level was to construct crises through setting ambitious goals. Hence, further study should attempt to isolate and describe some of the technological innovation capabilities (if any) that emerged within the context of the double helix formation where the university evolves from an ivory tower to become entrepreneurial.

In addition, future studies should try and address key challenges and the specific strategies utilized to overcome such challenges of both University and Industry during the double helix formation stage. Furthermore, the current pair-wise comparative case analysis offers a success story of the double helix formation stage within the context of the ivory tower being transformed and transitioned to become entrepreneurial under the initial wing of the Industry. However, given the possibility of other influencing factors relating to the circumstances and existing environments of the University and Industry during the double helix formation stage, such success stories cannot always be realized. Additionally, both the cases of POSTECH and SKKU suggest that within the Corporate Helix triad, there could also be a possibility for the acquisition of a public university by a public corporation or its establishment by government. In this context, the public corporation and government are able to establish, acquire, or form jointventures with a public university in case the public is averse to joint-ventures between the public school and the private sector. Therefore, future studies should identify and explore such trends in existing economies. Also, the case of the University of Ulsan and Hyundai Heavy Industries Group, as well as the case of LG Corporation, Cheonan Yonam College, and Yonam Institute of Digital Technology may offer alternate routes that both University and Industry could adopt to still undergo successful double helix formation. Both cases are currently being investigated by the author.

\section{Additional file}

Additional file 1: Multilingual abstracts in the five official working languages of the United Nations and Portuguese.

Competing interests

The author declares that he has no competing interests.

Authors' information

Dr. M-HC has been Professor at Konkuk University's Department of Biological Sciences since 1990 and Adjunct Professor for the American Government at University of Maryland University College. He holds a PhD in Microbiology and Immunology from the University of Arizona and a Master Degree in Public Administration from Harvard Kennedy School. He was a visiting scholar at Stanford University, President of AIDS Society of Asia and the Pacific, and co-Founder of Celltrion Inc. Dr. MHC capitalizes on his contextual familiarity in the national innovation system of South Korea to explain the helix phenomena for corporate-aligned universities within the context of emerging evolutionary markets. 
inspiration and guidance and Nicolette C. Prugsamatz at Mahidol University, College of Management, Thailand, for her technical insight and contribution.

Received: 24 January 2014 Accepted: 7 April 2014

Published online: 18 September 2014

\section{References}

ADB (Asian Development Bank) (2003) Special chapter: competitiveness in developing Asia. In: Asian Development Outlook 2003. Oxford University Press, New York

Amsden A (1989) Asia's next giant. Oxford University Press, New York

Bettis R, Hitt M (1995) The new competitive landscape. Strateg Manag J 16:7-19

Burgelman R, Maidique MA, Wheelwright SC (2004) Strategic management of technology and innovation. McGraw-Hill, New York, pp 8-12

Chang HJ, Park HJ, Yoo CG (1998) Interpreting the Korean crisis: financial liberalization, industrial policy and corporate governance. Camb J Econ 22:735-746

Cho MH (2008) Corporate Helix Model: the industry and triple helix networks. International Journal of Technology and Globalization 4(2):103-120

Cho MH (2013) Corporate Helix Model: triple helix networks for developing countries - a case of Samsung Corporation. Presented at the XI Triple helix conference, 8-10 July, 2013, London, UK

Choi H, Hwang Y, Kim W, Sung T, Lee D, Lee B, Kang Y, Lee K (2007) The evolution of public research systems of major countries and policy recommendation for Korea. In: STEPI policy report 2007-19 (In Korean with English abstract)

Dasgupta P, David PA (1994) Toward a new economics of science. Res Policy 23:487-521

Dierickx I, Cool K (1989) Asset stock accumulation and sustainability of competitive advantage. Manag Sci 35:1504-1511

Eichengreen B (2002) Capitalising on globalization. Asian Development Review 19(1):14-66

Eom BY, Lee K (2010) Determinants of industry-academy linkages and, their impact on firm performance: the case of Korea as a latecomer in knowledge industrialization. Res Policy 39:625-639

Etzkowitz H, Leydesdorff L (eds) (1997) Universities and the global knowledge economy: a triple helix of university-industry-government relations. Continuum, London

Etzkowitz H, Leydesdorff $L$ (2000) The dynamics of innovation: from national systems and "Mode 2" to a Triple Helix of university-industry-government relations. Res Policy 29:109-123

Etzkowitz H, Webster A, Gebhardt C, Terra BRC (2000) The future of the university and the university of the future: evolution of ivory tower to entrepreneurial paradigm. Res Policy 29(2):313-330

Eun J-H, Keun L, Wu G (2006) Explaining the "University-run Enterprises" in China: a new theoretical framework for university-industry relationship in developing countries and its applications to China. Res Policy 35:1329-1346

Fields K (1995) Enterprise and the State in Korea and Taiwan. Cornell University Press, Ithaca

Guan J (2002) Comparison study on industrial innovation between China and some European countries. Prod Invent Manag J 43(3-4):30-46

Hobday M (1995) Innovation in East Asia: the challenge to Japan. Edward Elgar, Aldershot

Hundt D (2005) A legitimate paradox: neo-liberal reform and the return of the state in Korea. The Journal of Development Studies 41(2):242-260

Hwang Y-S, Kim S-S, Byun B-M, Lee K-H, Lee H (2003) Strategies of promoting industry-academia-research institute R\&D partnerships to cope with new technologies-focusing on industry-research institute, interfirm R\&D partnerships. In: Policy research report R03-25. STEPI (Science \& Technology Policy Institute), Seoul, written in Korean

Innace JJ, Dress A (1992) Igniting steel: Korea's POSCO lights the way. Global Village, Huntington, p 202, 204-207

Kim L (1993) National system of industrial innovation: dynamics of capability building in Korea. In: Nelson RR (ed) National system of innovation: a comparative analysis. Oxford University Press, Oxford

Kim L (1997) Imitation to innovation: the dynamics of Korea's technological learning. Harvard Business School Press, Boston

Kim EM (1998) The four Asian tigers: economic development and the global political economy. Academic, San Diego

Kim L (1999) Building technological capability for industrializaion: analytical frameworks and Korea's experience. Ind Corp Chang 8(1):111-136

Kim EM (2000) Globalization of the South Korean chaebol. In: Kim S (ed) Korea's globalization. Cambridge University Press, Cambridge, pp 102-125

Kim S, Lee J (2006) Changing facets of Korean higher education: market competition and the role of the State. High Educ 52:557-587

Kong TY (2000) The politics of economic reform in South Korea: a fragile miracle. Routledge, London

Kwon K-S (2009) Emergence of research and entrepreneurial activities of Korean universities. Paper presented at the conference on university-industry linkages and economic performance, college of social sciences, Seoul National University, February 27, 2009

Lee JK (2006) Educational fever and South Korean higher education. Revista Electrónica de Investigación y Educativa $8(1): 1-14$

Lee H, Choi K, Yoon J, Kim G (1998) A study on the history of modern education after liberation from Japanese rule. Korean Educational Development Institute (KEDI), Seoul

Lim C (2006) Research issues derived from the study of national systems of innovation (NI) of small advanced national: analysis of the International Research Project on the NSIs of 10 small advanced nations. In: Policy research report 2006. STEPI (Science and Technology Policy Institute), Seoul, written in Korean

Lundvall BA (ed) (1992) National system of innovation: towards a theory of innovation and interactive learning. Pinter, New York

OECD (2008) OECD review of Korea's Innovation Policy. Interim report presented in Seoul. In: OECD Reviews of Innovation Policy: Korea July 2009

Park HW, Leydesdorff $L$ (2010) Longitudinal trends in networks of university-industry-government relations in South Korea: the role of programmatic incentives. Res Policy 39:640-649 
Pirie I (2005) The new Korean state. New Polit Econ 10(1):25-42

Wade R, Veneroso F (1998) The Asian crisis: the high debt model versus the Wall Street-Treasury-IMF complex. New Left Review 228:3-22

Wang JH (2007) From technological catch-up to innovation-based economic growth: South Korea and Taiwan compared. J Dev Stud 43(6):1084-1104

Weiss L (2000) Developmental states in transition: adapting, dismantling, innovating, not 'normalization'. Pac Rev 13(1):21-55

Weiss L (2003) Guiding globalization in East Asia: new roles for old developmental states. In: Weiss $L$ (ed) States in the global economy: bringing domestic institutions back in. Cambridge University Press, Cambridge, pp 245-270

Woo JE (1991) Race to the swift: state and finance in Korean industrialization. Columbia University Press, New York

Yam RCM, Guan JC, Pun KF, Tang EPY (2004) An audit of technological innovation capabilities in Chinese firms: some empirical findings in Beijing. China Research Policy 33(2004):1123-1140

Yam RCM, Lo W, Tang EPY, Lau AKW (2011) Analysis of sources of innovation, technological innovation capabilities, and performance: an empirical study of Hong Kong manufacturing industries. Res Policy 40:391-402

doi:10.1186/s40604-014-0002-1

Cite this article as: Cho: Technological catch-up and the role of universities: South Korea's innovation-based growth explained through the Corporate Helix model. Triple Helix 2014 1:2

Submit your manuscript to a SpringerOpen ${ }^{\circ}$ journal and benefit from:

- Convenient online submission

- Rigorous peer review

- Immediate publication on acceptance

- Open access: articles freely available online

- High visibility within the field

- Retaining the copyright to your article

Submit your next manuscript at $>$ springeropen.com 